\section{Rosa Maria Grillo}

Catedrática de Literatura Hispanoamericana en la Universidad de Salerno. Es autora de numerosos ensayos y monografías publicados en Italia, Francia, España y Uruguay sobre autores hispanoamericanos (Benedetti, Quiroga, Carlos Fuentes, J.J. Saer), sobre la narrativa de la emigración y de viaje, y sobre el papel de la novela histórica latinoamericana en la construcción de las identidades nacionales. Es miembro del Comité científico del Centro Estudios Mario Benedetti de Alicante y del Centro Studi Americanistici Circolo Amerindiano de Perugia y de sus respectivas revistas (América Sin Nombre y Thule) y publicaciones (Cuadernos de América sin nombre y Quaderni di Thule). Desde 2000 dirige la colección de narrativa latinoamericana A Sud del Rio Grande (Oedipus), que actualmente cuenta con ocho títulos.

Silvia Benso, "Le metamorfosi di Cíbola nei cronisti delle Indie», Letterature d'America, 6 (1981), p. 33.

2 Cf. Luigi Avonto, Mirando al otro, Montevideo, Universidad de la República, 1995, p. 255.

3

Respecto a la novela histórica «tradicional», romántica ○ realista, que generalmente se construye en apoyo a la historiografía oficial, podemos hablar de «nueva novela histórica», "novela histórica posmoderna» o «poscolonial», para indicar aquellos textos que re-escriben la Historia, adoptando un punto de vista alternativo y crítico hacia la historiografía oficial y utilizando técnicas "rupturistas» y «desrealizadoras» (cf. Rosa Maria Grillo, "La visione dei vinti nel romanzo storico latinoamericano», Annali dell'I.S.L.A 4 (2002), pp. 73-94)
Francisco del Puerto, Aguilar y Guerrero, tres náufragos entre la palabra y el silencio

pOSA MARIA GRILLO

\title{
FRANCISCO DEL PUERTO, AGUILAR Y GUERRERO, TRES NÁUFRAGOS ENTRE LA PALABRA Y EL SILENCIO
}

\author{
ROSA MARIA GRILLO
}

La historia del Descubrimiento y la Conquista está llena de náufragos y sobrevivientes a batallas y matanzas, protagonistas de «viajes» venturosos, que han permanecido un periodo más o menos largo entre los indígenas, como esclavos o destinados al sacrificio, sobreviviendo a peligros de toda índole, y con mucha suerte y astucia llegando a ser «dioses blancos y barbados» casi míticos. Pensemos en lo que nos cuentan sobre sus cautiverios o sus viajes Alvar Núñez Cabeza de Vaca en los Naufragios, Hans Ver Staden en Die wabrhaftige Histoire der wilden, nachten, grimmigen Menschfresser-Leute 1548-1555, Ulrico Schmidel en Relatos de la conquista del Río de la Plata y Paraguay 1534-1554 (Derrotero y viaje a España y las Indias), Jean de Léry en el Journal de bord en la terre de Brésil (1557). Sus historias representan otras tantas infracciones al canon que pretendía que se narrara sólo la historia de los grandes hechos protagonizada por héroes, y aunque partan de los cánones historiográficos impuestos a los cronistas oficiales (prólogo, justificación, afirmaciones de estricta referencia), los quebrantan en nombre de la singularidad de sus experiencias (en todos ellos se pasa de un «nosotros» que indica la comunidad de los descubridores y conquistadores al «yo» que impone un ritmo y un nivel totalmente subjetivos, hasta llegar a veces a un peligroso «nosotros» que incluye al «Otro»). Gracias a sus relatos,

La conoscenza dei territori e dei loro abitanti comincia a uscire dalla fase bellica della conquista per entrare in quella del contatto di popoli e persone [...]
Il rivelarsi di una realtà sconosciuta comincia ad avere valore in se stessa, e non solo in quanto spazio di terra che può essere assimilato e gestito dall'autorità istituzionale ${ }^{1}$.

Dejando sus memorias constituyen casos de involuntaria vanguardia de un conocimiento del «Otro» más profundo y, en parte, libre de los prejuicios y de las presiones que generalmente influyen en la escritura cronística oficial.

A estas relaciones autobiográficas hay que añadir lo que cuentan Sebastián Caboto de Francisco del Puerto, Enrique Montes y Melchor Ramírez, náufragos de la expedición de Solís al Río de la Plata, o Bernal Díaz del Castillo y Diego de Landa a propósito de Jerónimo de Aguilar y Gonzalo Guerrero, náufragos de la expedición de Valdivia entre los indianos de Yucatán, y un largo etcétera. Aguilar y Guerrero, además, constituyen una "pareja opositiva» muy interesante: sus diferentes reacciones frente a la llegada de los mensajeros de Cortés se vuelve paradigmática de la elección entre «civilización» y «barbarie», entre razón y locura -uno volviendo al mundo «civil» y otro permaneciendo voluntariamente en la «barbarie», totalmente «indianizado» y consecuentemente borrado por la Historia-, mientras que Francisco del Puerto es aún hoy un caso no resuelto ${ }^{2}$.

A estos náufragos, a sus relatos o a su silencio y a su experiencia inquietante o misteriosa, la «nueva novela histórica» ${ }^{3}$ latinoamericana ha dirigido repetidamente su mirada, por ser materia adecuada a operaciones de reinterpretación y revisión de la historia oficial 
y presentación de aquellas aventuras no como bajada al infierno de la barbarie, sino como experiencia antropológica de contacto con el Otro y su cultura. Es decir, sin modificar la Historia la reinterpretan, ya que es conquista reciente la de aseverar que toda escritura, también la historiográfica y la realista, más que reflejar y copiar la realidad, la significa e interpreta ${ }^{4}$.

Mucho se ha escrito tanto sobre Cabeza de Vaca y su testimonio como sobre el «silencio» de los demás. En el primer caso, pensamos por ejemplo en la novela de Abel Posse El largo atardecer del caminante, que imagina al viejo caminante escribiendo sus memorias «verdaderas», contradiciéndose a sí mismo y a cuanto tuvo que escribir $-y$ callar- para no desagradecer al Consejo de Indias y a la Santa Inquisición. Pero no es éste el caso que me interesa aquí, sino lo que se ha escrito a partir del silencio de aquellos náufragos que, por diferentes razones, han desaparecido de la Historia.

Pensemos en un personaje inquietante, apenas mencionado en las crónicas pero muy utilizado por los novelistas, como Francisco del Puerto. Éste fue el único superviviente de un ataque de los indios que en 1516 mataron a Juan Díaz de Solís y a sus compañeros en el Río de la Plata, y fue rescatado diez años más tarde por la expedición de Sebastián Caboto. En realidad los cronistas e historiadores de entonces afirmaron que no sobrevivió nadie, y sólo Sebastián Caboto en 1530, en la Información hecha por los Oficiales de la Casa de Contratación de Sevilla luego que llegó la armada de Sebastián Caboto, acerca de lo que le ocurrió en el viaje, da noticia de este náufrago y de su hallazgo:

este declarante [Caboto] falló un Francisco del Puerto, que habían prendido los indios cuando mataron a Solís, el cual le dio grandísimas nuevas de la riqueza de la tierra; y con acuerdo de los capitanes e oficiales de Su Majestad acordó de entrar en el Río Paraná fasta otro Río que se llama Caracarañá, que es donde aquel Francisco del Puerto les había dicho que descendía de las sierras donde comenzaban las minas del oro e plata 5 .

Pero la figura de Francisco del Puerto, apenas llegado a los umbrales de la Historia, se difumina y las noticias se vuelven ambiguas y contradictorias. Demasiado incómoda es de hecho la continuación de la historia, que sólo muy pocos investigadores recientes han «descubierto»: en el mismo juicio de Caboto, él y varios testigos más afirman que Francisco tuvo un enfrentamiento con el tesorero Gonzalo Núñez y

por esto cree este declarante [Caboto] quel dicho Francisco los vendió a los dichos indios; e queste declarante, viendo este desbarato e toda la tierra revuelta, se tornó a donde había fecho la casa ${ }^{6}$.

José Toribio Medina, en su monumental El veneciano Sebastián Caboto al servicio de España, intenta resumir y explicar el ambiguo suceso: el 10 de abril de 1528, a la boca del Río Paraguay, Francisco del Puerto fue a hablar con los indígenas que invitaron a los españoles a un banquete al que acudieron entre 16 y 20 marineros, entre ellos el tesorero Núñez y el mismo Francisco. Pero era una emboscada sobre cuyas motivaciones hay dos versiones:

la de Ramírez ${ }^{7}$, que asegura fue a causa de que se hallaban temerosos de que los españoles fuesen a vengar la muerte de los compañeros de Díaz de Solís [...] y la de Caboto, que la atribuía á venganza de Francisco del Puerto por el odio que había cobrado a Núñez después del desagrado que entre ellos medió. Esta última nos parece que es mucho más aceptable que la primera [...] Según Caboto la invitación de los indios se verificó después que Francisco del Puerto estuvo con ellos [...] y por fin porque Francisco del Puerto no regresó a bordo. Quedaría sólo por saber si a causa de haber perecido también, o si después de vengado ya, volvió a su antigua vida con los salvajes. Todo induce a creer que fue esto último lo que ocurriós .

Nadie más habla de Francisco del Puerto y su nombre no aparece ni entre los que volvieron a España, ni entre los que murieron. $\mathrm{Pa}$ rece lógico pensar que se haya quedado entre los indios, y una confirmación en este sentido parece venir de una investigación reciente: Eduardo Bueno, hablando de la marcha por tierra que el gobernador del Río de la Plata Alvar Núñez Cabeza de Vaca cumplió en 1541 desde la costa atlántica (Porto dos Patos, cerca de la actual ciudad de Florianópolis) hasta Asunción del Paraguay por un difícil camino trazado por los indígenas, anota que en el actual estado brasileño de Paraná Cabeza de Vaca se encontró con un misterioso hombre blanco que dijo llamarse Francisco ${ }^{9}$. Siendo el territorio del Alto Paraná el mismo donde llegó Caboto y tuvo lugar la traición, es posible pensar que se trate del mismo Francisco, aún vivo en 1541 (recuérdese que cuando se
Roland Barthes, "Historical Discourse», en Michael Lane, Introduction to Structuralism, New York, Basic Books, 1970, pp 153-154.

5

Sebastián Caboto, "Declaración de Caboto», en Avonto, op.cit. p. 260. Cf. También Rosa Maria Grillo, «El viaje de Francisco del Puerto de las crónicas a las novelas», Quaderni di Thule, 2 (2003), pp. 200-212.

Sebastián Caboto, cit. en José Toribio Medina, El veneciano Sebastián Caboto al servicio de España, Santiago de Chile, Imprenta Universitaria, 1908, II p. 160.

Luis Ramírez, marinero español embarcado con Caboto, autor de una Carta a su padre repetidamente citada por los estudiosos del descubrimiento del Río de la Plata.

8

Toribio Medina, op.cit., I, pp. 168-169.

Cf. Eduardo Bueno, Capitâes do Brasil, Río de Janeiro, Objetiva, 1999, pp. 128-129.
Francisco del Puerto, Aguilar y Guerrero, tres náufragos entre la palabra y el silencio

ROSA MARIA GRILLO 


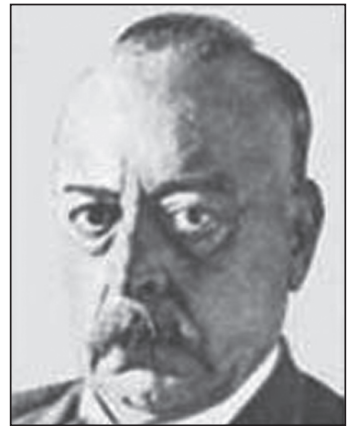

Roberto J. Payró.

10

Roberto J. Payró, El mar dulce, Buenos Aires, Losada, 1974, p. 219. Francisco del Puerto aparece marginalmente también en otras novelas de Payró.

Francisco del Puerto, Aguilar y Guerrero, tres náufragos entre la palabra y el silencio

ROSA MARIA GRILLO embarcó, en 1515, era un grumete, con unos 13 o 14 años de edad).

La primera parte de la aventura de Francisco del Puerto es un caso no demasiado excepcional, pero es la segunda parte la que deja abiertas muchas puertas interpretativas y por lo tanto atrae más a los «nuevos» novelistas. Si los cronistas e historiadores parecen haberse quedado en la primera parte del relato de $\mathrm{Ca}$ boto (si no se le menciona más, el ser recogido por Caboto presupone el regreso), una mayor atención a la otra historia, la de los vencidos y los silenciados, ha permitido investigar más sobre el sino de Francisco del Puerto y sobre el silencio que lo ha acompañado: si hubiera regresado, su relato de los diez años entre los indios, contado por él mismo o por algún solícito cronista, bien hubiera podido competir con el de Cabeza de Vaca y demás náufragos-cronistas. En cambio, si Francisco del Puerto renuncia a la civilización para quedarse en la barbarie, caería en el olvido y en el silencio porque su caso sería inexplicable para el eurocentrismo imperante. Hay muchas semejanzas entre el destino de Francisco y el de Gonzalo Guerrero: en ambos casos se ha hablado de una posible traición, pero sobre ellos los cronistas e historiadores han impuesto el silencio, haciéndolos «desaparecer» de la Historia, ya que la traición no sólo no estaba prevista en el imaginario de los cronistas, sino que era inadmisible e inexplicable, y además dar a conocer esta noticia podía ser muy peligroso y deseducativo porque era una infracción al Orden, a la Verdad y a la Civilización. Si antes de la deposición de Caboto y de sus oficiales en Sevilla en 1530 se decía que no había ningún superviviente de la expedición de Solís, después se corrige esta versión pero sin llegar nunca a la conclusión: sólo el silencio y el vacío de la no-historia, la historia de los vencidos.

La incertidumbre del destino de Francisco del Puerto y su inexplicable silencio (¡cómo podía callarse quien había vivido tal experiencia!) empujan a antropólogos e historiadores (Daniel Vidart, Renzo Pi Hugarte, José Toribio Medina, Eduardo Acosta y Lara, Francisco A. Bauzá), ya en el siglo XX, a investigar y narrar su historia. En el afán de reivindicaciones y progenituras, ahora Francisco del Puerto ha salido de la nada, es un personaje discutido y estudiado, y en el Prado montevideano hasta se le ha dedicado una calle.

También tres escritores argentinos, Roberto R. Payró, Juan José Saer y Gonzalo Enrique Marí, han contado esa historia, eligiendo tres finales diferentes, que representan formas y sentidos opuestos de mirar al pasado, a la conquista, a España y a América: Payró deja el relato abierto, pero todo lleva a pensar en un regreso, físico e ideológico, a lo europeo; Saer elige el regreso, aunque con una mirada muy «indianizada»; Marí plantea decididamente la opción de su «indianización», lo que confirma cómo el género de la novela histórica llega a ser un instrumento al servicio de la ideología del escritor, quien elige y moldea según su necesidad acontecimientos históricos que, en cuanto averiguables, confieren a la novela cierto aire de objetividad.

El mar dulce de Payró en 1927 podía proponer una visión positiva y civilizadora del descubrimiento e indicar en Francisco del Puerto el primer poblador español del Río de la Plata, es decir la raíz y el principio de la identidad rioplatense. Todo esto va en la línea del «redescubrimiento» de España y de la reivindicación del sustrato heroico y épico español iniciados por Rodó y el modernismo: orgullosa afirmación de la identidad criolla, amenazada por el aluvión migratorio de principios de siglo y por el nuevo imperialismo yanqui. Para que así se pueda leer la aventura de Francisco del Puerto, Payró omite también el encuentro con Caboto, y la última imagen es la del grumete que ve pasar las expediciones siguientes:

Pero símbolo o vaticinio, el adolescente, el tierno vástago de la estirpe secular, Francisco del Puerto, cautivo de los indios, quedaba a orillas del Mar Dulce donde reverdecería y crecería, como tronco apenas recordado de la primera anónima rama de criollos del Río de la Plata. Realización de un sueño en forma no soñada, sus descendientes habían de ver que las pobres tierras de desengaño escondían en realidad tesoros inagotables, más perennes que el oro y que la plata. Vinieron años de olvido y abandono. Después, en el noble río penetraron otros navegantes en otras carabelas, y Paquillo les vio llegar; les vio llegar y les vio marcharse, burlados también, pese a su intrepidez y su esperanza. Y las tentativas, trágicas a veces, repitiéronse y fracasaron de nuevo en estas regiones hostiles, mientras no se encontró su llave, hecha de trabajo, de tenacidad y de $\mathrm{fe}^{10}$.

El Paquillo de Payró se queda en una actitud de espera, mirando los barcos pero sin sumarse a ellos, inseguro ante su futuro: podrá reincorporarse al mundo civilizado o, si se queda, asumir la identidad del «Otro». Ni las crónicas, como hemos visto, ni esta novela nos dan a conocer su elección: en las prime- 
ras, lo vemos perdido en el silencio, mudo como toda la gente anónima de su rango; en la segunda, lo vemos por última vez como el náufrago que era, en el aislamiento y la incomunicación total, incapaz de elegir su destino. Pero Payró no tiene dudas: cualquiera sea la elección de Francisco, y sin traicionar la Historia, con un final abierto, muy moderno $\mathrm{y}$ ambiguo, su figura puede prestarse al mito fundacional y ser funcional para el designio argentino de aquellos años. Una vez más, narrar una historia del pasado significa escribir sobre el presente, y el presente de Roberto Payró era de fe en el gran porvenir de una Argentina española, civilizada por el sacrificio de sus primeros descubridores.

Al contrario, en los años ochenta del siglo $\mathrm{XX}$, durante una crisis económica y política de gran intensidad, la Argentina se interroga sobre su pasado y sobre su identidad: $E l$ entenado (1983) de Juan José Saer, novela de formación en forma autobiográfica, pone en tela de juicio toda la conquista, la política y la ética española de la época del descubrimiento. El anónimo narrador, bien reconocible en Francisco del Puerto ${ }^{11}$, ya viejo y establecido en España, cuenta su viaje de ida al Nuevo Mundo y de regreso al mundo «civilizado» como pautas que cierran su experiencia entre los indios, que reconoce como fundamental. No hay indicaciones paratextuales o extratextuales que indiquen la voluntad de Saer de tergiversar o cambiar la Historia para fundamentar su tesis y por lo tanto podemos presumir que Saer conocía la versión más difundida, la que ve a Francisco recogido por Caboto, y que a partir de allí ha construido su relato: la del grumete viene a ser una traición ideológica y sentimental a la Weltanschaunng europea, no menos grave y acusadora que la posible traición concreta de Francisco del Puerto, y sus interrogantes, sus dudas, sus recuerdos, empujan al lector a interrogarse sobre la Verdad, profunda, epistemológica, filosófica, de aquel hecho y de toda la historiografía de los vencedores.

En estos 50 años que separan la novela de Saer de la de Payró el revisionismo historiográfico ha hecho estragos de las certezas históricas e ideológicas de la modernidad: la civilización por antonomasia ya no es la occidental, se persigue una nueva estructuración de la Historia a través de la recuperación de las «historias» hasta entonces olvidadas, de los vencidos, los marginales, los silenciados. En este ámbito adquiere nuevo sentido la escritura de novelas históricas, entendidas ya no como discurso sobre la construcción de una nacionalidad o una identidad colectiva, como en la novela de Payró, sino como deconstrucción de la Historia oficial: «La historia se escribe por parte de quienes triunfan; los que pierden escriben novelas», afirma el protagonista de Pepe Botellas ${ }^{12}$.

Si los triunfadores del hecho histórico de la conquista -cronistas y autores de novelas históricas tradicionales- escriben en tercera persona para otorgar mayor veracidad a lo que afirman, o en primera plural para indicar la pertenencia a un mismo destino histórico, quien quiere dar su versión alternativa de la Historia, ya modernamente consciente de que el discurso historiográfico, siendo discurso y no acción, conlleva por definición cierta dosis de subjetivismo -de ficcionalidad-, habla en primera, acentuando aún más su perspectiva y su cosmovisión personal. Hemos visto que en la novela de Payró hay un narrador omnisciente, dueño de la historia que está contando y conforme con la historia de los vencedores; en la novela de Saer, el «yo» pseudoautobiográfico narra un trayecto de dudas y de difícil maduración, con continuas alternancias de tiempos verbales, pronombres personales, elementos referenciales de pronombres posesivos o deícticos. Por ejemplo, durante el viaje de ida es dominante un «nosotros» que abarca no sólo la tripulación del barco sino todo aquel mundo del que cada marinero o soldado se sentía partícipe ( La alegría fue grande; aliviados, llegábamos a orillas desconocidas que atestiguaban la diversidad» ${ }^{13}$ ), pero, a partir de la muerte del capitán, se impone un yo individual y totalmente subjetivo

En pocos segundos, mi situación singular se mostró a la luz del día: con la muerte de esos hombres que habían participado en la expedición, la certidumbre de una experiencia común desaparece y yo me quedaba solo en el mundo ${ }^{14}$.

Así, solo y desnudo como cuando nació, desprendido de lo anterior -madre, patria, familia, grupo- y necesitado de encontrar otras certidumbres, acaba por aceptar rápidamente la nueva realidad como natural. Paulatinamente, Francisco se asimila al grupo indígena, superando tabúes y preconceptos europeos («yo, el eterno extranjero, no quería quedar afuera» ${ }^{15}$ ) hasta llegar a un «nosotros» que delata la salida de la incomunicabilidad y del aislamiento y la asimilación a un nuevo grupo (típico de la novela de formación). Mensaje positivo -utópico y nostálgico a la vez- que
11 No hay indicadores geo-cronológicos precisos ni nombres, pero hay indicios y alusiones que ayudan al lector a «reconocer» el hecho.

12

Gustavo Álvarez Gardeazábal, Pepe Botellas, Bogotá, Plaza y Janés, 1984, p. 88.

13

Juan José Saer, El entenado, México D.F., Folios, 1983, p 16.

14

Ibid., p. 27.

15

Ibid., p. 45.

Francisco del Puerto, Aguilar y Guerrero, tres náufragos entre la palabra y el silencio

ROSA MARIA GRILLO 


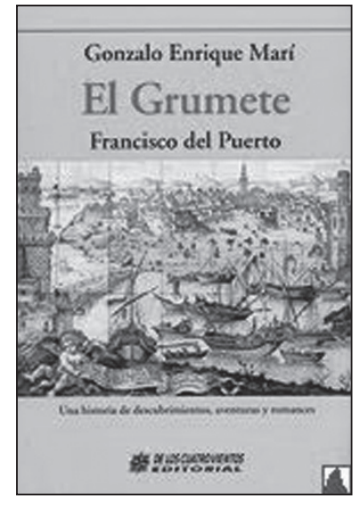

Portada de El grumete Francisco del Puerto, de Gonzalo Enrique Marí.

16

Alvar Núnez Cabeza de Vaca, Naufragios, Madrid, Taurus, 1962, p. 124.

17

Juan José Saer, cit. por Fernando Ainsa "La reescritura de la historia en la nueva novela latinoamericana», Cuadernos de Cuadernos, 1 (1991), p. 29.

\section{8}

Aunque no se pueda hablar de «poscolonialismo» en sentido histórico estricto, la búsqueda de una "tercera vía» que no se corresponda a las opciones socio-políticas del viejo mundo, la toma de conciencia de un destino y una identidad no-europeos, la emergencia en todos los ámbitos de la voz y la perspectiva indígena y mestiza que quebrantan la indiscutida -hasta las últimas décadas del 900- voz imperante del Occidente, permiten equiparar la condición hispanoamericana a la de los países de África, Asia y Antillas de más reciente independencia. Se puede pensar en el fenómeno del «poscolonialismo» como en la otra cara de la "posmodernidad», que se puede definir muy someramente como la pérdida de la función céntrica de «lo occidental», que conlleva naturalmente fenómenos de la fragmentación, lecturas subversivas del «canon» etc.

19

Gonzalo Enrique Marí, El Grumete Francisco del Puerto, Buenos Aires, De los Cuatro Vientos Editorial, 2003, p. 137

20

Ibid., p. 172. tiene su «texto paralelo» en los Naufragios, en aquel «nosotros» utilizado por Núñez Cabeza de Vaca en el momento de reintegrarse a su mundo, metáfora de la condición de extraño en sentido geográfico y cultural: «Dimos a los cristianos muchas mantas de vaca y otras cosas que traíamos; vímonos con los indios en mucho trabajo porque se volviesen a sus casas» ${ }^{16}$. Pero si en la realidad de la España del siglo XVI Núñez Cabeza de Vaca tuvo que olvidar, que borrar de su memoria y de su escritura elementos del "contagio» para que no se le cerraran las puertas del Paraíso, dejando sólo indicios y silencios llenos de interrogantes, en la ficción de este fin de siglo precisamente aquel «contagio» se vuelve nudo emblemático y llave de lectura de todo el texto: un contagio que llega hasta el presente, ya que, como afirma el mismo autor,

no se reconstruye ningún pasado sino que se construye una visión del pasado, cierta imagen del pasado que es propia del observador y que no corresponde a ningún hecho histórico preciso ${ }^{17}$.

Así, podemos leer las diferencias entre la novela de Payró y la de Saer como el viaje de Francisco del Puerto desde la participación a un proyecto de edificación de la identidad y de la nacionalidad a uno de cuestionamento y deconstrucción de lo ya adquirido: el no-regreso había dejado al protagonista de Payró en la etapa de la modernidad, como el arquetipo del hombre moderno exportador de experiencia y fundador de civilización (un Robinson Crusoe ante litteram), mientras que el regreso en la novela de Saer otorga la posibilidad de alejarse para poder ver mejor y comprender, de meditar y reinventar el sentido de la Historia desde el punto de vista "poscolonial» ${ }^{18} \mathrm{de}$ reivindicación del escritor latinoamericano de otras raíces y otros orígenes, rechazando «lo europeo» como único patrón.

En una novela reciente del argentino Gonzalo Enrique Marí, El grumete Francisco del Puerto (2003), Francisco del Puerto aparece totalmente indianizado, y cumple la traición. Marí llena el silencio de la Historia entre la muerte de Solís y la llegada de Caboto utilizando varios modelos narrativos, desde los Naufragios de Cabeza de Vaca -y El entenado de Saer- para describir el canibalismo: tristes y taciturnos como eran [los charrúas], no se jactaron de la ceremonia, degustaron la carne de sus enemigos sin alegría. Por venganza, por odio, sin duda no por hambre, más bien por poseer las virtudes del otro y reafirmar las propias ${ }^{19}$.

También se hace referencia a mitos y leyendas guaraníes para la construcción del mito del «dios blanco» enviado por el Karaì Jeupie para conducir a los guaraníes hacia la Tierra sin Mal. Parece que Marí quiera «salvar» todas las posibilidades interpretativas de la aventura de su grumete: por una parte, lo indica como fundador de la identidad rioplatense parafraseando a Payró y dando muy modernamente énfasis sobre el rol fundacional del lenguaje

Juntos [él y la india Jasyrendy] inventaron una nueva lengua, o al menos la lengua castellana adquirió otra musicalidad en las costas del Paraná20.

Por otra parte, le confiere el papel de «enviado divino y portador de la palabra de Karaí Jeupie, Karaí Pitaguá o Sacerdote Extranjero" ${ }^{21}$. El encuentro con Caboto es simplemente descriptivo y el autor deja entre líneas cualquier comentario o juicio sobre los reales proyectos del grumete, que se ofrece para acompañar a los españoles como lengua y guía, mientras que es bien explícito en enseñar las intenciones de Caboto:

Los buenos oficios de Francisco le estaban rendiendo sus frutos, por lo que se mostró animado y afable con él. Ya llegaría el momento oportuno para cortarle el pescuezo de un sablazo 22 .

Pero luego Francisco traiciona y hace que un grupo de españoles, al mando de Miguel de Rifos, caiga en una emboscada y sea destruida una de las carabelas, pero no puede impedir que los españoles destruyan el pueblo donde había vivido. No falta un final feliz, y al reencontrarse con Jasyrendy descubre que ya ha nacido su hijo mestizo: otra solución que confirma la adhesión a la versión de Payró de Francisco del Puerto como «fundador» de la Argentina futura, pero subrayando las raíces autóctonas más que las españolas, y acercándose más a la elección voluntaria de Gonzalo Guerrero de quedarse en su nueva patria. Marí por lo tanto asume totalmente la versión de la traición de Francisco, y aunque sea una novela formalmente tradicional -tercera persona, narrador omnisciente, explicaciones e his-
Francisco del Puerto, Aguilar y \begin{tabular}{c} 
palabra y el silencio \\
\hline
\end{tabular}

ROSA MARIA GRILLO
21

lbid., p. 234.
22

Ibid., p. 239 
torias entrelazadas pero ordenadas- nos da otra versión de la Historia.

Resumiendo, podemos decir que en estas novelas hay diferencias notables en el tratamiento de la Historia, correspondientes a las diversas dominantes culturales de la modernidad y del pensamiento poscolonial: discurso positivista, eurocéntrico, conforme con la versión tradicional de la Historia, invisibilidad de la escritura que se acerca al patrón de grado cero del nivel científico-referencial, en Payró; al contrario, discurso revisionista y deconstructivista, crítico hacia la Historia y la cultura eurocéntricas y respetuoso de la alteridad, introspectivo y consciente de que no es posible detectar la verdad fuera del discurso que la enuncia, en Saer; en Marí, aunque la forma sea tradicional, nos encontramos con la versión de los vencidos, que en este caso serían tanto Francisco como los indios, borrados por la historiografía oficial. Sin duda podemos también afirmar que las tres responden a un mismo dictado: escribir sobre el pasado para hablar del presente dando, en cualquier caso, una interpretación ideológica del suceso narrado. Por lo tanto constituyen, más que la ficcionalización de la Historia - una de las definiciones posibles de novela histórica- la politización de la misma, casi una declaración de la no-neutralidad de cualquier interpretación y discurso de y sobre la Historia.

Me he detenido tanto sobre las tres lecturas de la historia de Francisco del Puerto hechas por Payró, Saer y Marí porque representan tres diversas opciones, que se pueden referir también a Aguilar y Guerrero, los dos náufragos de la expedición del capitán Valdivia de quien Cortés oyó hablar al pisar tierra mexicana.

Efectivamente, en los mismos años algo parecido acontece también en lo que será la Nueva España conquistada por Cortés. Si el Gran Capitán en sus Cartas de relación casi no nombra a los dos náufragos, porque su relato sólo se ocupa de los grandes Hombres -y, sobre todo, de sí mismo- Bernal Díaz del Castillo desde su óptica diferente no duda en rescatarlos del olvido: muchas líneas dedica a Aguilar -e indirectamente a Guerrero- que así recupera su justo lugar en la Historia (lo nombra cincuenta y ocho veces), no sólo por su oficio reconocido -ser «lengua»- sino también por otras tareas suyas como la evangelización ("cosas tocantes a nuestra santa fe [que] fueron muy bien declaradas, porque doña Marina y Aguilar, nuestras lenguas, estaban ya tan experto en ello, que se lo daban a entender muy bien»). Diego de Landa es aún más explícito: los náufragos

de dolencia murieron quedando solos Gerónimo de Aguilar y Gonzalo Guerrero, de los cuales Aguilar era buen cristiano y tenía unas horas por las cuales sabía la fecha [...] éste se salvó con la ida del marqués Hernando Cortés [...] y Guerrero, como entendía la lengua, se fue a Chectemal [...] allí le recibió un señor llamado Nachancán, el cual le dio a cargo las cosas de la guerra en que tuvo muy bien, venciendo muchas veces a los enemigos de su señor, y que enseño a los indios pelear [...] y que con esto y con tratarse como indio, ganó mucha reputación y le casaron con una muy principal mujer en que hubo hijos; y que por esto nunca procuró salvarse como hizo Aguilar, antes bien labraba su cuerpo, criaba cabello y harpaba las orejas para traer zarcillos como los indios y es creíble que fuese idólatra como ellos [...] Aguilar, recibida la carta [de Cortés] atravesó en una canoa el canal entre Yucatán y Cuzmil y [...] viéndole los de la armada fueron a ver quién era; y [...] Aguilar les preguntó si eran cristianos y respondiéndole que sí, y españoles, lloró de placer y puestas las rodillas en tierra dio gracias a Dios [...] los españoles lo llevaron a Cortés así desnudo como venía, el cual le vistió y mostró mucho amor; y [...] Aguilar contó allí su pérdida y trabajos y la muerte de sus compañeros y cómo fue imposible avisar a Guerrero en tan poco tiempo por estar más de ochenta leguas de alli²3.

En esta narración sólo aparentemente neutra, Diego de Landa propone una lectura religiosa de la diferente elección ya que fue el «ser buen cristiano» de Aguilar lo que le permitió salvarse y volver a la civilización, mientras que Guerrero -con su marca negativa con respecto a la fe- parecía predestinado a ser idólatra. Otros cronistas e historiadores no se alejan de esta versión, subrayando siempre la innatural, bárbara e inexplicable decisión de Guerrero y, al contrario, el buen carácter y la religiosidad de Aguilar.

En las novelas históricas del siglo XIX, por supuesto, se confirma la versión historiográfica de los vencedores, con palabras de encomio hacia Aguilar y silencio sobre Guerrero. Una excepción la constituye Eligio Ancona, autor de numerosas novelas históricas sobre la conquista, que en 1864 publica La cruz y la espada, en la que dedica un capítulo entero a Guerrero, aunque «de segunda mano»: la india Zuhuy Kak cuenta al joven español Benavides la historia de amor entre su madre Kayab y Guerrero, a quien la noble india había conseguido salvar del sacrificio. Sólo el amor hacia su mujer y sus tres hijos,
23

Diego de Landa, Relación de las Cosas de Yucatán, México D.F., Monclem Ediciones, 2000 pp. 26-31. Entre los cronistas e historiadores no hay acuerdo sobre la actuación de Aguilar si consiguió o no hablar con Guerrero invitándolo a volver con los españoles.
Francisco del Puerto, Aguilar y Guerrero, tres náufragos entre la palabra y el silencio

ROSA MARIA GRILLO 


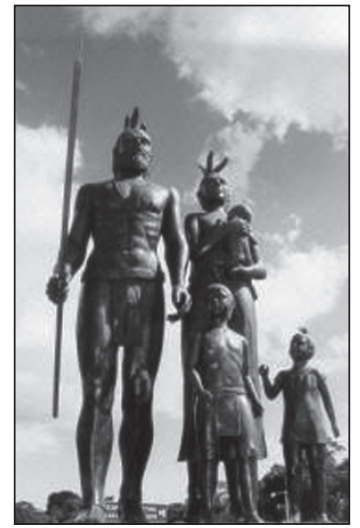

Monumento al mestizaje (Gonzalo Guerrero y Zazil Há), situado a la entrada de Othón P. Blanco (Quintana Roo).

\section{4}

Eligio Ancona, La cruz y la espada, Mérida, Editorial Yucatanense Club del Libro, 1950, pp. 85-86.

25

Fernando Benítez, La ruta de Hernán Cortés, México D.F., F.C.E., 1964, pp. 98-102.

Francisco del Puerto, Aguilar y Guerrero, tres náufragos entre la palabra y el silencio

ROSA MARIA GRILLO y no una «indianización» sacrílega, impidió a Guerrero reintegrarse como Aguilar al campo español,

pero desde aquel día empezó a marchitarse como las hojas de los árboles en el ardiente estío de nuestro país. El recuerdo de la patria, principalmente cuando se tiene esperanza de volverla a ver, es muy triste y doloroso en una tierra extranjera, por grandes que sean los goces que nos proporcione [...] Dos años después de la partida de Aguilar, bajaba al sepulcro, invocando el nombre de su Dios y de su patria ${ }^{24}$.

Ya viuda sin consuelo, Kayab después de unos cuantos años se casó con un cacique de un pueblo cercano, de cuya unión nació Zuhuy Kak. En esta novela, mientras se confirma la imagen de Aguilar «buen cristiano» presente en las crónicas, se corrige la de Guerrero, siempre indicado como bárbaro y traidor, aquí presentado como hombre débil y víctima del sentimiento paternal, pero siempre fiel a su Dios y a su patria. No se habla de una posible traición de Guerrero anterior a la llegada de Cortés, y haciéndolo morir sólo dos años después, además, se evita el espinoso problema de su presencia o, peor aún, su jefatura en las batallas que en Yucatán los indios libraron en contra de los españoles. Se corrige la Historia, rehabilitando a Guerrero, pero fundamentalmente no cambia el discurso sobre la Conquista y su papel civilizador y evangelizador.

El primero en dar una lectura diferente sobre esta pareja tan dispar es Fernando Benítez, quien en 1950 escribe La ruta de Hernán Cortés: relatando su propio viaje y siguiendo la ruta de los conquistadores, cuenta asimismo la conquista de México proponiendo su propio discurso sobre la Historia: Aguilar

no tiene vocación de náufrago. Apocado y falto de iniciativa, desde el principio se resigna a no ser otra cosa que un esclavo [...] Algunos cronistas han querido ver en él, si no a un santo, por lo menos a un beato, y hasta se intentó poner su vida como ejemplo y enseñanza de náufragos disolutos [...], llega incluso a olvidarse de su español: su única lectura es la de su inseparable libro de horas, escrito en latín [...] Pero, bajo la apariencia de indio, vive insobornable su espíritu de occidental. No ama la tierra que le ha deparado el destino, ni se mezcla a sus hombres, ni deja huella fecunda de su paso. Es en todo mediocre. Como intérprete de la expedición, queda oscurecido por Doña Marina y nunca se distingue en la guerra o en otra actividad por nada notable. Al final, arrastrado por el heroísmo de sus camaradas, tratará de ador- nar su historia de náufrago con el cuento de haber sido elevado por los indios al rango de capitán, pero la desastrosa situación en que se le halla hecha por tierra su mentira. Gonzalo Guerrero, en cambio, no goza de buen crédito en las crónicas de la conquista. Se le considera un traidor a su sangre y a su cultura y aun se llega a decir que fue el inspirador de las batallas que libraron los indios de Yucatán contra los primeros expedicionarios españoles. Fuera de estas referencias, sólo tenemos de él las noticias amañadas que presentó Aguilar, porque de los renegados no gustan ocuparse los historiadores.

Así comenta, al final, la historia de los dos robinsones, consignando al olvido el buen Aguilar y rescatando al bárbaro Guerrero:

Uno pasó sin dejar rastro de su larga estancia en México. Tenía una educación que lo hacía impermeable a la asimilación y al arraigo. El marinero iletrado, aunque su nombre y el de su descendencia se hayan perdido, quedará como el del primer español que sintió el llamado de nuestra patria. Fue el primer desarraigado europeo que unió sus destinos a los de una india anónima, y sus tres guapos chicos, asimismo, nuestros primeros mestizos ${ }^{25}$.

Aun quedando firmemente anclado en la Historia, con este comentario y con la alusión a una posible intervención de Guerrero contra la expedición de Hernández de Córdoba, sin condenarla, Fernando Benítez se pone como un innovador en la historiografía sobre la Conquista y como un pionero de la nueva novela histórica.

La profecía de Benítez se ha cumplido: Aguilar nunca es protagonista de una obra de ficción, aunque aparezca en muchas, con muy pocas diferencias de juicio sobre su figura -siempre es un buen cristiano $\mathrm{y}$ «hombre sin calidades»- mientras que el silencio de Guerrero deja abiertas más posibilidades, aunque naturalmente no todos los «nuevos» novelistas siguen la ruta de Benítez.

En una novela reciente, con un paratexto muy sugerente y aparentemente subversivo (Como conquisté a los aztecas, escrito por «Hernán Cortés con la colaboración de Armando Ayala Anguiano», 2006) que dejaba vislumbrar una posibilidad narrativa similar al Cabeza de Vaca de Abel Posse, nada nuevo se añade ni se corrige a la Historia oficial de la conquista de México. El autor no tiene ninguna intención crítica o paródica, y hasta me parece una perspectiva miope y torpe ya que afirma que se inspiró, además que en las Cartas de Cortés, en los estudios sobre el mundo 
azteca de Alfonso Caso, Ignacio Bernal, Miguel León Portilla etc., y que «las opiniones de Cortés coincidían seguramente con las de estos investigadores» ${ }^{26}$. Todo esto, sin ironía alguna. El Cortés de Ayala Anguiano cuenta el encuentro con Aguilar según la mejor tradición de las crónicas, y su comentario no deja lugar a dudas acerca de la ortodoxia de la novela:

Entre nosotros túvose por gran misterio y milagro de Dios el contratiempo que nos hizo regresar a $\mathrm{Co}$ zumel, ya que de otra manera Aguilar se habría quedado en la península y no hubiese hecho los grandes servicios que nos prestó. Como hablaba muy bien la lengua maya, lo hice mi intérprete de confianza, pues yo siempre sospeché que el Melchorejo no decía a los indios lo que yo le indicaba, sino lo que él les quería decir, que era muy contrario a lo que convenía a nuestro servicio ${ }^{27}$.

Aguilar será hasta el final intérprete de confianza, mientras sobre Guerrero cae el silencio más absoluto, después de la descripción que de él hace Aguilar: «tenía labrada la cara y horadadas las orejas [y] tres hijos, a quienes quería tanto» ${ }^{28}$. Fiel también en esto al discurso presente en las Cartas de Cortés, Ayala Anguiano no reconoce a la Malinche el rol insustituible que le reconocieron Díaz del Castillo y demás cronistas, y por lo tanto Aguilar puede ser hasta el final de la novela intérprete de confianza.

En cambio, en otras novelas cuya protagonista es la Malinche, Aguilar aparece, siempre con un papel secundario, como antagonista de la mujer: generalmente va perdiendo importancia y significado histórico a medida que ella va ganando la confianza de Cortés y aprende milagrosamente español. Caso emblemático es la novela de Laura Esquivel, $M a-$ linche (2005): el narrador omnisciente puede penetrar alternativamente en las mentes de Cortés y Malinche y siembra astutamente todo el texto de signos premonitores del destino de la Malinche como dueña de la palabra («tus palabras nombrarán lo aún no visto y tu lengua volverá invisible a la piedra y piedra a la divinidad», le dijo un «tlaciuhque que leía los granos de maíz» cuando aún era una niña ${ }^{29}$ ) y de indicios, al contrario, de la escasa confianza que Cortés tiene en el fraile rescatado

No sabía hasta dónde el fraile Jerónimo de Aguilar era fiel a sus palabras o era capaz de traicionarlas [...] Aguilar resultó muy útil como intérprete entre Cortés y los indígenas de Yucatán, pero no había mostrado habilidad alguna para la negociación y el convencimiento ya que, de haberla tenido, las primeras batallas entre españoles e indígenas no habrían sido necesarias ${ }^{30}$.

Paulatinamente Aguilar desaparecerá de la escena para dejar el campo a la Malinche, verdadera «dueña de la palabra» y del poder que ésta otorga. Guerrero, en cambio, adquiere papel de protagonista en numerosas nuevas novelas históricas, siendo su historia -su no-historia- susceptible de las más variadas interpretaciones.

Eugenio Aguirre, por ejemplo, hereda completamente la posición de Fernando Benítez y no duda en proponer a Gonzalo Guerrero como un conquistador conquistado, a quien los mexicanos de hoy elevan un canto:

En la leyenda ha quedado tu nombre, estrella de sangre, rubia gema que viniste a acrisolar la raza, la nueva estirpe, la cósmica aventura de los nuevos pueblos; ave que anidaste en el bronceado lecho de la carne morena del Mayab para engendrar los hábitos ancilares de la cultura joven de América ${ }^{31}$.

Aguirre acierta en relatar el proceso de «indianización» de Guerrero como un proceso discontinuo, difícil, con inevitables nostalgias y perplejidades, contado en primera persona por el mismo Guerrero desde la muerte que lo cogió mientras guiaba su tribu en una desigual batalla contra la expedición de Lorenzo de Godoy:

esa mañana [...] ladraron los perros como nunca lo habían hecho, graznó el moán en mis oídos con una estridencia que sólo yo pude entender, y la lechuza ululó en el camino que tomamos [...] Fue un combate cara a cara, cuerpo a cuerpo y, en el fragor, un estampido vino a quebrarme la vida, vino a opacarme la luz y a sumirme en las tinieblas eternas... era el año del Señor de mil y quinientos treinta y seis ${ }^{32}$.

A esta confesión póstuma -alternada a capítulos en tercera persona, de carácter histórico- se debe la reconstrucción de esta conversión, desde una condición de asimilación superficial (ir desnudos y participar en los ritos tribales, por ejemplo) a una de creíble construcción sincrética. Cuando le nació la primera hija, con rasgos evidentes de mestiza - «blanca, de ojos celestes y nariz afilada»-fue inmediatamente

consciente de que era el producto de dos razas totalmente distintas, separadas por circunferencias

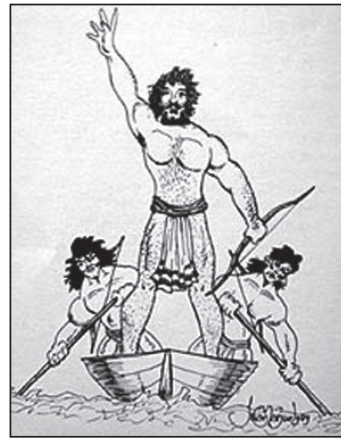

Jerónimo de Aguilar (dibujo).

\section{6}

Armando Ayala Anguiano, Cómo conquisté a los aztecas (por Hernán Cortés con la colaboración de Armando Ayala Anguiano), México D.F., Debolsillo, 2006, p. 10.

27 Ibid., p. 47.

28 Id. 29 Laura Esquivel, Malinche, México D.F., Santillana Ediciones Generales, 2006, pp. 26-27.

30 Ibid., pp. 40-41.

31 Eugenio Aguirre, Gonzalo Guerrero, México D.F., Punto de Lectura, 2004, p. 420.

32

lbid., p. 419
Francisco del Puerto, Aguilar y Guerrero, tres náufragos entre la palabra y el silencio

ROSA MARIA GRILLO 
33

Ibid., p. 331.

34

lbid., pp. 323-324.

35

Ibid., p. 124

36

Es un caso opuesto al de Marí, donde a la forma tradiciona se acompañaba un contenido subversivo.

37

Fray Joseph de San Buenaventura, Historias de la conquista del Mayab, Edición, Paleografía, Introducción y Notas de Gabriela Solís Robleda y Pedro Bracamonte y Sosa, Mérida, Univer sidad Autónoma de Yucatán, 1994 , p. 69.

38

Ibid., p. 71.

39

Ibid., p. 91.

40

Ibid., p. 16.

41

Carlos Fuentes, "Las dos orillas», en Los cinco soles de México, Barcelona, Seix Barral, 2000, p. 44.

Francisco del Puerto, Aguilar y Guerrero, tres náufragos entre la palabra y el silencio

ROSA MARIA GRILLO cósmicas de muy diferente trayectoria [...] Bien sabía que lo extraordinario es el alimento favorito de los dioses y que su apetito demanda viandas de tal jaez. Desde entonces me preocupé por asimilarle completamente a las costumbres y tradiciones del pueblo, con el fin de que no sufriese cuando se le pidiese la entrega capital, el epílogo de su existencia; como al final de cuenta acaeción ${ }^{33}$.

También se aludirá a la racional decisión de dar guerra a los españoles:

Fui escarbando en mi memoria, rescatando del pasado lo que pudiese servirme para juzgar [a los españoles] y logré reproducir una secuencia de actos malvados, de una crueldad singular, perpetrados en la carne de los caribes, en los pobres negros traídos como esclavos desde el África [...] Columnas de encadenados con grilletes, conducidas por los representantes de Dios en la Tierra, para que cultivasen las parcelas de los hombres de sotana y rosario; negros obligados a tener comercio carnal con sus hermanas, con sus madres, con sus hijas, para que el amo, el santo varón de la Compañía de Jesús, tuviese mano de obra fresca en los cañaverales, en los trapiches [...] Fue suficiente para mí, y que la historia me juzgue como lo crea pertinente ${ }^{34}$.

Esta alusión al juicio de la Historia es naturalmente polémica y crítica hacia la Historia oficial, actitud evidente también en las múltiples alusiones a la «inexactitud de los cronistas» ${ }^{35}$, y en las numerosas citas entre comillas de crónicas españolas e indígenas, glosadas y corregidas por el narrador-protagonista.

No siempre la atención que se le presta a Guerrero es de matriz «revisionista» de la Historia oficial. Opuesta a la de Aguirre es la versión presente en otro texto que, como el de Ayala Anguiano, está compuesto con un paratexto intrigante: Fray Joseph de San Buenaventura, franciscano prisionero entre los indios yucatecos de 1696 a 1697, aparece como autor de Historias de la conquista del Mayab publicado en México en 1725, y ahora (1994) publicado por Gabriela Solís Robleda y Pedro Bracamonte y Sosa (Edición, Paleografía, Introducción y Notas). No hay dudas de que se trata de una novela contemporánea, aunque escrita «a la manera de...», recurso muy propio de la nueva novela histórica aunque en el contenido no haya una subversión de la Historia ${ }^{36}$. Mientras en la obra de Eugenio Aguirre es fácilmente rastreable su proyecto político de indicar en Guerrero el primer español cautivado por la cultura indígena -que hasta defiende con las armas en contra de sus compatriotas- y su trayectoria aparece totalmente creíble y fascinadora, en esta Historias de la conquista del Mayab el autor intenta mantenerse en un difícil equilibrio entre las diversas opciones, presentando un hombre que no renuncia nunca a su fe originaria y sigue creyendo en la misión evangelizadora de la Conquista: «si no les dais vosotros las batallas, ellos en jamás os la darán a vosotros, que se vienen de paz y os traen la buena andanza y mejor bienestar» ${ }^{37}$. Para no escuchar lo que cuentan los hombres sobre las violencias de los españoles, rehuye de su compañía y hasta de la de sus hijos que

hacen mucho caso de la madre y en nada creen en mí [...] y mi hijo don Gonzalo que mírame a mí con recelo y más cautela que en nada quiere oír las mis palabras de darle la mejor explicación de todas las cosas que aquí acaecen ${ }^{38}$.

Se propone como lengua, neutral e ingenua, en un improbable encuentro entre su tribu y el capitán don Francisco de Montejo, y hasta le está permitida la neutralidad, ya que quien conduce a los indios a la batalla no es él, sino su hijo don Gonzalo de Guerrero Kan Xiu. Cautivado éste por los españoles, su padre consigue liberarlo gracias a la intervención de unos frailes misioneros:

Dios nuestro señor a quien habemos nosotros pedido tan señalada merced [...] ha movido a compasión al señor capitán don Francisco de Montejo y os otorgará la merced que le habéis pedido y os entregará vivos y buenos y sanos a los dos mancebos mayas, que el uno de ellos es vuestro hijo ${ }^{39}$.

Cosa muy extraña en una obra tan «ortodoxa» es la descripción que se hace de Aguilar que, en medio de la tormenta, «empezó a votar blasfemias y palabras soeces» ${ }^{40}$. Es sólo un detalle insólito y no adecuado al personaje Aguilar, que en el resto sigue las pautas de las crónicas.

Finalmente, también Aguilar toma su revancha, relatando su verdadera historia en el cuento «Las dos orillas» (El naranjo, 1993) de Carlos Fuentes. El escritor mexicano, que en su trabajo ensayístico casi no nombra a los dos náufragos, en este cuento los hace protagonistas de una historia realmaravillosa: el yo narrador pertenece a Jerónimo de Aguilar y su punto de vista, desde una «perspectiva olímpica» ${ }^{41}$, es alternativo y disidente e incluso presenta una posibilidad histórica des- 
conocida que adelantaría a la llegada misma de Cortés a la bahía de Veracruz la fecha del primer proyecto de rebelión antiespañola en tierra americana.

Las fuentes historiográficas habían separado decididamente las vidas de los dos náufragos: Fuentes, en cambio, los une en la común elección de matar a Cortés:

si yo me fui con Cortés y Guerrero se quedó en Yucatán, fue por común acuerdo. Queríamos asegurarnos, yo cerca de los extranjeros, Guerrero cerca de los naturales, que el mundo indio triunfase sobre el mundo europeo ${ }^{42}$.

Pero el plan fracasó («la culpable fue una mujer» ${ }^{43}$ ) no sólo porque, al ser la amante de Cortés, la Malinche tuvo un poder mayor, sino porque impuso su palabra:

Una vez más, fue la intérprete doña Marina la que decidió la contienda, aconsejándole con fuerza al rey [...]; los extranjeros, pero también esta tabasqueña traidora, eran dueños de un vocabulario vedado por Moctezuma $^{44}$.

No fue suficiente que Aguilar diera a Moctezuna «el secreto de la debilidad de Cortés, como doña Marina le había dado a Cortés el secreto de la debilidad azteca: la división, la discordia, la envidia» ${ }^{45}$, porque Aguilar nunca pudo competir con Malinche y Cortés «en las artes del disimulo, la treta y la pausa» ${ }^{46}$. La Malinche gana definitivamente la competición con Aguilar aprendiendo español:

ya no hacía falta, la hembra diabólica lo estaba traduciendo todo, la tal Marina hideputa y puta ella misma había aprendido a hablar el español, la malandrina, la mohatrera [...] la coima del conquistador, me había arrebatado mi singularidad profesional, mi insustituible función, vamos, por acuñar un vocablo, mi monopolio de la lengua castellana [...]; la lengua era más que la dignidad, era el poder; y más que el poder, era la vida misma que animaba mis propósitos» ${ }^{47}$.

Porque, como Fuentes ha escrito en El espejo enterrado,

cuando todo había terminado, cuando el emperador Moctezuma había sido silenciado por su propio pueblo, cuando el propio conquistador, Hernán Cortés, había sido silenciado por la Corona de España que le negó poder político en recompensa a sus hazañas militares, quizás sólo la voz de la Malinche permaneció. La intérprete, pero también la amante, la mujer de Cortés, la Malinche estableció el hecho central de nuestra civilización multirracial, mezclando el sexo con el lenguaje [...] La Malinche parió hablando esta nueva lengua que aprendió de Cortés, la lengua española, lengua de la rebelión y la esperanza, de la vida y la muerte, que habría de convertirse en la liga más fuerte entre los descendientes de indios, europeos y negros en el hemisferio americano ${ }^{48}$.

El Aguilar de Fuentes es un personaje totalmente inédito, no sólo por su opción política: no es el fraile asexuado y timorato de las crónicas sino un hombre atrevido y rebelde, que confiesa su amor a la Malinche y sueña con involucrarla en su proyecto para ser, los dos juntos, «dueños de las lenguas [...] dueños de las tierras, pareja invencible porque entendíamos las dos voces de México, la de los hombres pero también la de los dioses» ${ }^{4}$.

Lo que hace Fuentes es rellenar el hueco entre el naufragio y el re-encuentro de los dos náufragos con una historia compartida-Aguilar, la palabra, Guerrero, el brazo-, como un proceso paralelo hacia la «indianización»:

Entramos a esa vida naturalmente, porque no teníamos otro horizonte, es cierto, pero sobre todo porque la dulzura y dignidad de esta gente nos conquistó [...] Su [de Guerrero] voluntad y la mía, el arte de armar barcos -y el de ordenar palabras- se juntaron $y$ juramentaron en silencio, con una inteligencia compartida y una meta definitiva... ${ }^{50}$.

Aguilar, relatando esta historia desde el otro mundo («desde la muerte, [tiene] todo el tiempo del mundo para narrar» ${ }^{51}$ ), convertido en estrella para poder acompañar a su amigo Guerrero en el viaje hacia España, confirma el papel que tuvo Guerrero en el ataque indio a la expedición de Francisco Hernández de Córdoba, y hasta imagina que Cortés,

como si adivinara su propio destino [...] dejó a Guerrero entre los indios para que un día acometiese esta empresa, réplica de la suya, y conquistara a España con el mismo ánimo que él conquistó a México, que era el de traer otra civilización a una que consideraba admirable pero manchada por excesos, aquí y allá: sacrificio y hoguera, opresión y represión, la humanidad sacrificada siempre al poder de los fuertes y al pretexto de los dioses... ${ }^{52}$.

Pero, sobre todo, relata la trama de la alianza entre los dos náufragos que lleva al inesperado desenlace: están convencidos de que sólo el poder regenerador de ritos, cere-

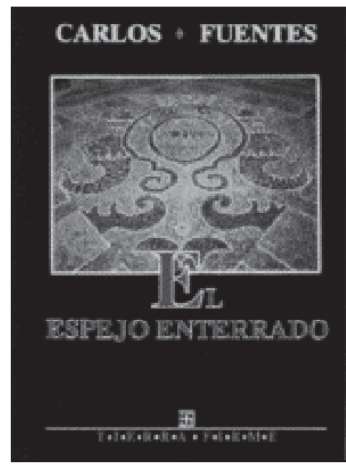

Portada de El espejo enterrado, de Carlos Fuentes.

42

Ibid., p. 72

43

Ibid., p. 50.

44

Ibid., p. 55

45

Ibid., p. 56.

46

Ibid., p. 55

47

lbid., pp. 60-62.

48

Carlos Fuentes, El espejo enterrado, Madrid, Alfaguara, 1997 , p. 161

49

Fuentes, "Las dos orillas», op.cit., p. 67.

50

lbid., pp. 71-73.

51

Ibid., p. 79

52

lbid., p. 78.
Francisco del Puerto, Aguilar y Guerrero, tres náufragos entre la palabra y el silencio

ROSA MARIA GRILLO 
53

Ibid., p. 75.

54

lbid., pp. 76-77.

55

Carlos Fuentes, Cervantes o la crítica de la lectura, Alcalá de Henares, Centro de Estudios Cervantinos, 1994, p. 84.

56

Fuentes, "Las dos orillas», op.cit., p. 57.
Francisco del Puerto, Aguilar y Guerrero, tres náufragos entre la palabra y el silencio

ROSA MARIA GRILLO monias, mitos, imaginación mágica de los indígenas, a través de la palabra, podía regenerar también al viejo mundo. Junto con Guerrero, Aguilar se empeñó

en fortalecer esta misión y en devolverle a nuestra tierra española de origen el tiempo, la belleza, el candor y la humanidad que encontramos entre estos indios... Pues la palabra era, al cabo, el poder gemelo que compartían los dioses y los hombres [...] Desde mi tumba mexicana, yo animé a mi compañero [...] para que contestase a la conquista con la conquista; ya fracasé en mi intento de hacer fracasar a Cortés, tú, Gonzalo, no debes fracasar, haz lo que me juraste que haría $5^{53}$.

Una vez conquistada España, Guerrero empieza la edificación de un mundo sin fronteras:

el templo de las cuatro religiones, inscrito con el verbo de Cristo, Mahoma, Abraham y Quetzalcóatl [...] Dulces cantos mayas se unieron al de los trovadores provenzales, la flauta a la vihuela, la chirimía a la mandolina, y del mar cerca del Puerto de Santa María emergieron sirenas de todos los colores, que nos habían acompañado desde las islas del Caribe... Cuantos contribuimos a la conquista india de España, sentimos de inmediato que un universo a la vez nuevo y recuperado, permeable, complejo, fecundo, nació del contacto entre las culturas, frustrando el fatal designio purificador de los Reyes Católicos ${ }^{54}$.

No podría ser más explícito el discurso de Carlos Fuentes que, como en todos sus escritos, apunta a renovar el sueño de un mestizaje profundo y creativo, capaz de valorizar todos los elementos de una cultura milenaria y mestiza como la española, que por culpa del «fatal designio purificador de los Reyes Católicos» no supo respetar la otrosí milenaria cultura mesoamericana, ni mezclarse con ella.

Como conclusión, podemos intentar llevar a cabo una lectura de las novelas sobre Francisco del Puerto, Jerónimo de Aguilar y Gonzalo Guerrero, como un macrotexto sobre el tema del náufrago y sus posibles opciones frente a la civilización y la barbarie, términos cuyos referentes son determinados histórica, ideológica y culturalmente. Rellenar de una forma u otra aquel hueco historiográfico entre el naufragio y el re-encuentro, aceptar la versión oficial o hurgar en lo nodicho o sólo aludido de las crónicas, imaginar otra historia y confesiones o diarios secretos de los náufragos para explicar sus decisiones, es naturalmente una elección nunca ingenua y sí de fuerte significado político: es la contribución que hace cada autor a la lectura de la Historia de la Conquista, y, podemos decir, de los más de 500 años de vida de lo hispanoamericano.

El Paquillo de Payró, que se queda entre los indígenas, sería el Guerrero de las crónicas, de quien ya nadie hablará, mientras que el de Saer, que regresa a España, sería un Aguilar que se adueña de la palabra autónoma -ya no simplemente esclavo de la palabra ajena- para contar sus experiencias. Este Francisco ha tomado la «justa» decisión, pero su análisis no deja lugar a dudas sobre dónde está la barbarie y dónde la civilización: ya en España, no le queda más remedio que ficcionalizar, en su tardía experiencia teatral, la nostalgia y la pérdida; con Marí hay, en cambio, el relato explícito de las suposiciones de Caboto borradas por la Historia, que tiene su paralelo en la historia de Guerrero contada por Aguirre: lúcida decisión de quedar en aquella barbarie americana que resulta ser la verdadera civilización. Las novelas de Armando Ayala Anguiano y de Laura Esquivel siguen fielmente, en cambio, el dictado de la historiografía española, mientras una solución intermedia es la de las Historias de la Conquista del Mayab, donde Guerrero no es cautivado por la civilización india, sino por su mujer y sus tres hijos mestizos.

A la luz de lo dicho, el relato de Carlos Fuentes resulta fantástico sólo aparentemente, ya que se asemeja mucho a las «verdaderas historias» de Francisco (contada por Marí) y de Gonzalo (contada por Aguirre), negadas por la Historia oficial que prefirió borrar a quien se arrimó a los vencidos en una desesperada tentativa de cambiar la Historia. Con mucha maestría, Carlos Fuentes unifica los destinos divergentes de los tres náufragos en una síntesis altamente significativa que ratifica el compromiso de todo escritor latinoamericano: dar voz a los silencios de la Historia aunque esto signifique inventar su propia historia ya que, como escribe en Cervantes, $o$ la crítica de la lectura, «El arte da vida a lo que la historia ha asesinado. El arte da voz a lo que la historia ha negado, silenciado o perseguido. El arte rescata la verdad de las mentiras de la historia $\aleph^{55}$ o, como afirma por boca de Aguilar, «cuando palabra, imaginación y mentira se confunden, su producto es la verdad ${ }^{56}$. 